\title{
Numerical Simulation of GTM Asphalt Mixture Design Parameters Based on Discrete Element
}

\author{
Li Shanqiang ${ }^{1, ~ a, ~ L i ~ H a o ~}{ }^{2, b}$ and Xu Xinquan ${ }^{3, \mathrm{C}}$ \\ ${ }^{1}$ School of Road, Chang'an University, Xi'an 710064, Shanxi, China \\ ${ }^{2}$ Research and Development Center on Road Transport Safety and Emergency Support \\ Technology \& Equipment, Ministry of Transport, PRC, Guangzhou 510420, Guangdong, China; \\ ${ }^{3}$ Guangdong Hualu Communications Technology Co.LTD, Guangzhou 510420, Guangdong, China

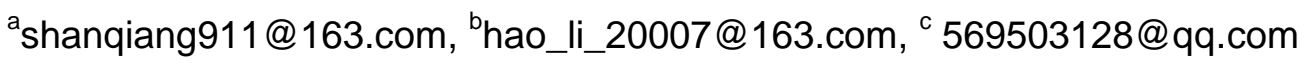

Keywords: Discrete element; GTM method; Asphalt mixture; GSI;GSF

Abstract. The laboratory compaction method produces a huge effect on the design of mix proportion and performance testing of asphalt mixes. For the result of a performance test to yield reliable physical properties, it is necessary to ensure that laboratory specimens are fabricated in a manner that adequately simulates field compaction. However, the laboratory compaction based on Gyratory Testing Machine(GTM) is closed to field compaction.

This study simulated the compacting process of asphalt mixes based on GTM, and analyzed the displacement, stress and strain to changes in mold in order to reveal the physical properties during compacting by using discrete element theory.

The results indicated that the design method based on GTM is reasonable and adaptability, and the basic requirements that GSI must be less than or equal to 1.0,and GSF must be great than or equal to 1.0 is scientific. What is more, the study presents the reasonable value range of design parameters to GSI and GSF for engineering application, which is referred to in the study as GSI can be less than or equal to 1.05 , and GSF can be great than or equal to 1.3.

\section{Introduction}

The corps of engineers invents Gyratory Testing Machine in the United States in the $1960 \mathrm{~s}$ in order to solve the design and research of air heavy bombers airport pavement, and it is in ASTM specification in 1978 in the United States ${ }^{[1]}$.The basic premise of the GTM method of surface courses mix design is that the test should empoly the tire contact pressure and compact the test specimen to the pavement density that will ultimately develop in a roadway under traffic ${ }^{[2]}$. The design density and bitumen content should be those values corresponding to the minimum bitumen content at which an increase in the gyratory angle is observed ${ }^{[3]}$. For bitumen contents higher than this the bitumen begins to display aggreate and the phenomenon of reduction in shear strength with increased compaction occurs. This manifests itself during the GTM compaction test by a progressive increase in the gyratory angle and by a reduction in roller pressure ${ }^{[4]}$.

However, the GSF value obtained should exceed one in order to insure against permanent shear deformation ie rutting in the wheel path. The GSF is not a valid measure of measure of stability when the GSI value exceed one because a GSI value greater than one indicates that the mix is on the rich side of compaction curve and progressive rutting will occur under hot weather traffic[5]. What is more, some researchers in China consider that the GSI value should less than or equal to 1.05 and the GSF value should exceed 1.3. The standard was more applied in Hebei province[6]. However, the value of GSI and GSF is an empirical value without a theory.It is necessary to follow some methodologies to model to study the reasonable value range of GSI and GSF.

\section{Analysis of GSI and GSF}

Gyratory Stability Index is expressed as the radio of measured shear strain $\theta_{\max }$ at equilibrium state to the induced minimum shear strain $\theta_{\min }$, ie GSI $=\theta \max / \theta \mathrm{min}$. As shown in figure 1 (a). The factor of 
safety with regard to shear is expressed as the ratio of measured shear strength $S_{\mathrm{G}}$ to the induced maximum shear $\tau \max$, ie $\mathrm{GSF}=\mathrm{S}_{\mathrm{G}} / \tau_{\max } . \mathrm{SG}$ is calculated by Eq. 1, the meaning of parameters is shown in figure $1(\mathrm{~b})$.

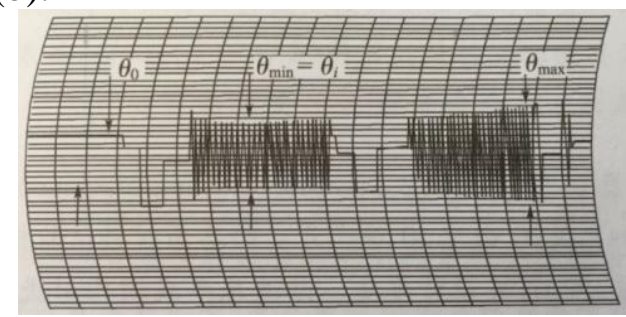

(a) the relationship between shear strain and times

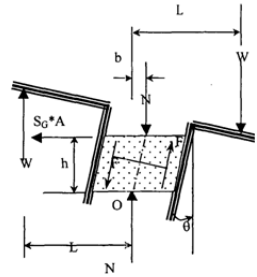

(b) mechanical characteristic

Fig. 1 parameters of GTM

$$
\mathrm{S}_{\mathrm{G}}=\frac{2 \times(\mathrm{P} \times \mathrm{L}-\mathrm{F} \times \mathrm{a})+\mathrm{Nxb}}{\mathrm{Axh}} \times\left(\frac{\theta_{\max }}{\theta_{0}}\right) \quad \text { Eq. } 1
$$

In addition, a stable mix does not show a significant increase in the gyratory angle during the compaction and the roller pressure does not show a significant decrease.

Modeling and analysis of mechanism of GSI. Whether stress and strain is in the elastic or plastic deformation range when asphalt mixture occurs a rotation angle can be considered as the decision criteria of the allowed angle, namely the value judgement standard of the GSI value.

Uniformly distributed load $\mathrm{P}$ is on both ends of asphalt mixture which use rigid board restrictions on both sides. When the reference angle is $\theta$, the rotation angle $\mathrm{A}$ of rigid plate is regarded as input, taking a analysis of the internal stress and strain response of asphalt mixture.At this point, $\theta$ can be regarded as the induced minimum shear strain $\theta \mathrm{min},(\theta+\mathrm{A})$ can be regarded as the measured shear strain $\theta \max$ at equilibrium state. Gyratory Stability Index is expressed as the radio of $(\theta+\mathrm{A})$ to $\theta$, ie $\mathrm{GSI}=(\theta+\mathrm{A}) / \theta$.

Taking $\mathrm{P} 、 \theta$ and $(\theta+\mathrm{A}) / \mathrm{A}$ as variables, $\mathrm{P}=0.7 \mathrm{MPa} 、 0.9 \mathrm{MPa} 、 1.1 \mathrm{Mpa}, \theta=00,0.80,1.2 \mathrm{o}$, $(\theta+A) / A=1.0,1.05,1.08$. Through different combinations of the value of variables, the reasonable value range of GSI can be inferred by judging whether stress and strain is in the elastic or plastic deformation range.

Modeling and analysis of mechanism of GSF. As shown in fig.1(b), shear strength $S_{G}$ is calculated based on two-dimensional model which contains a series of assumptions without considering vertical pressure and the viscoelasticity-anelasticity of asphalt mixture. The paper bulids two-dimensional numerical analysis model to explain shear strength $\mathrm{S}_{\mathrm{G}}$.

Using static analysis model, uniformly distributed load $\mathrm{P}$ is on both ends of asphalt mixture. Taking $\mathrm{P}$ and $\theta$ as variables, $\mathrm{P}=0.7 \mathrm{MPa} 、 0.9 \mathrm{MPa} 、 1.1 \mathrm{Mpa}, \theta=0^{\circ} 、 0.8^{\circ} 、 1.2^{\circ}$. Building the relationship between $S_{G}$ and $W$. The reasonable value range of GSF can be inferred by comparing the relationship with Eq. 1.

\section{Numerical simulation based on the discrete element}

Particle Follow Code 2 Dimension (PFC2D) is a kind of effective means to simulate the movement and interaction of circular particle medium the solid mechanics and particle flow problem.

The structure model in PFC2D software is a two-dimensional aggregate made up of hundreds to tens of thousands of typical circular particles, which assumed to be the rigid body. The internal force between particles based on GTM is transmitted through the contact and bite, the deformation of material under loads comes from sliding, rotation, opening and closure along the contact surface between particles mainly. It can be inferred that numercial simulation based on the discrete element can reveal the physical properties of asphalt mixture based on GTM.

The asphalt mixture particle can be considered as the particle flow code unit when modeling. Structuring different shape of asphalt mixture particles, and simulating the effects of particles in asphalt mixture.Using four basic shape of particles and their combination to study the changing rules 
of the displacement, deformation and stress in the process of compaction. As shown in fig.2(a). Numerical simulation model and boundary conditions are shown in fig.2(b) and (c).

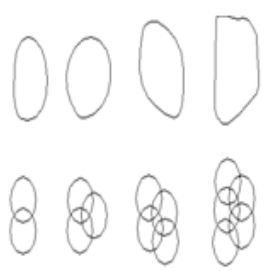

(a) particle shape

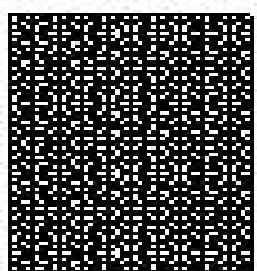

(b)model

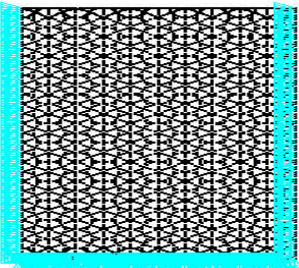

(c) boundary conditions

Fig. 2 Numerical simulation analysis

The basic parameters of asphalt mix are shown in Table 1 and Table 2, temperature is shown in Table 3.

Table 1 Mechanical parameters

\begin{tabular}{|c|c|c|c|c|c|c|c|c|}
\hline $\begin{array}{c}\text { Particle } \\
\text { paraments }\end{array}$ & Number & $\begin{array}{c}\text { Initial void } \\
\text { ratio } \\
(\%)\end{array}$ & $\begin{array}{c}\text { dry density } \\
\left(\mathrm{g} / \mathrm{cm}^{3}\right)\end{array}$ & $\begin{array}{c}\text { Diameter } \\
(\mathrm{mm})\end{array}$ & $\begin{array}{c}\text { Normal } \\
\text { contact } \\
\text { stiffness } \\
(\mathrm{N} / \mathrm{m})\end{array}$ & $\begin{array}{c}\text { Tangential } \\
\text { contact } \\
\text { stiffness } \\
(\mathrm{N} / \mathrm{m})\end{array}$ & $\begin{array}{c}\text { Normal } \\
\text { bond } \\
\text { strength } \\
(\mathrm{N})\end{array}$ & $\begin{array}{c}\text { Tangential } \\
\text { bond } \\
\text { strength } \\
(\mathrm{N})\end{array}$ \\
\hline $\begin{array}{c}\text { Asphalt } \\
\text { mix }\end{array}$ & 2000 & $15 \%-16 \%$ & 3 & $0.075-26.5$ & $8.2 \times 10^{8}$ & $6.0 \times 10^{8}$ & 0 & 0 \\
\hline
\end{tabular}

Table 2 Other parameters

\begin{tabular}{|c|c|c|c|c|c|}
\hline $\begin{array}{l}\text { Elasticity } \\
\text { modulus } \\
(\mathrm{MPa})\end{array}$ & $\begin{array}{c}\text { Normal elasticity } \\
\text { coefficient } \\
\mathrm{kn}(\mathrm{MPa})\end{array}$ & $\begin{array}{l}\text { Tangential } \\
\text { elasticity } \\
\text { coefficient } \\
\text { kt(MPa) } \\
\end{array}$ & $\begin{array}{c}\text { Damping } \\
\text { coefficient of the } \\
\text { quality } \\
(\alpha)\end{array}$ & $\begin{array}{l}\text { Friction } \\
\text { coefficient } \\
\qquad(\mu)\end{array}$ & $\begin{array}{l}\text { Time step } \\
\text { (s) }\end{array}$ \\
\hline 2.2 & $\mathrm{~Eb} / 2(\mathrm{R} 1+\mathrm{R} 2)$ & $0.2 \mathrm{kn}$ & 0.05 & 0.3 & 0.0005 \\
\hline
\end{tabular}

Table 3 The value of temperture $\left({ }^{\circ} \mathrm{C}\right.$ )

\begin{tabular}{|c|c|c|c|c|}
\hline Field temperature & Paving temperature & Initial pressure & Re-pressing & Termination \\
\hline $160 \sim 170$ & $150 \sim 160$ & $140 \sim 160$ & $135 \sim 150$ & $90 \sim 100$ \\
\hline
\end{tabular}

\section{Results of numerical simulation}

\section{Results of GSI.}

$(\boldsymbol{\theta}+\mathbf{A}) / \mathbf{A}=\mathbf{0 . 9 5}$. Partial enlarged vector diagram of stress, strain and displacement deformation is shown in fig.3. All of them turn out to be elastic changes, uniform distribution and no obvious plastic deformation.

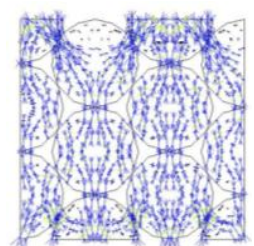

(a) principal stress

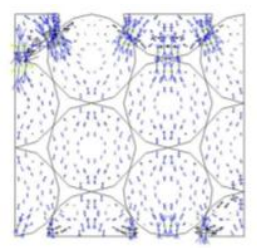

(b) principal strain

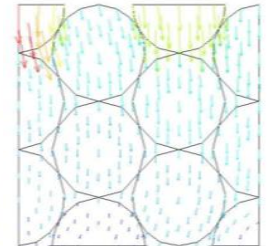

(c) displacement

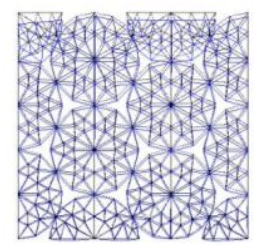

(d) deformation

Fig.3 Partial enlarged vector diagram $(\theta+A) / A=0.95$

$(\boldsymbol{\theta}+\mathbf{A}) / \mathbf{A}=\mathbf{1 . 0 0}$. Partial enlarged vector diagram of stress, strain and displacement deformation is the same with $(\theta+A) / A=0.95$. All of them turn out to be elastic changes, uniform distribution and no obvious plastic deformation.

$(\boldsymbol{\theta}+\mathbf{A}) / \mathbf{A}=\mathbf{1 . 0 5}$. Most of them turn out to be elastic changes, uniform distribution. But plastic deformation occurs, which is not so large to cause damage. As shown in fig.4.

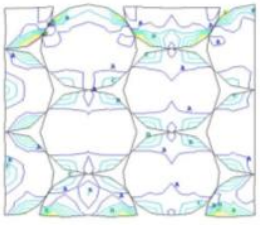

(a) principal stress

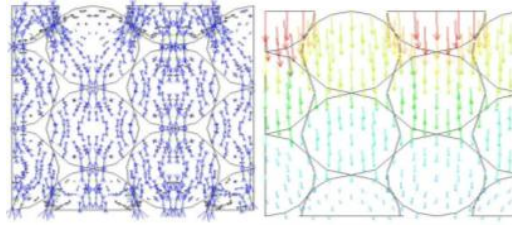

(b) principal strain

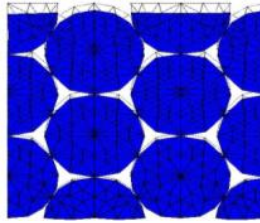

(c) displacement

(d) deformation

Fig.4 Partial enlarged vector diagram $(\theta+\mathrm{A}) / \mathrm{A}=1.05$ 
$(\boldsymbol{\theta}+\mathbf{A}) / \mathbf{A}=\mathbf{1 . 0 6}$. Plastic deformation is lagrer and the plastic damage occurs, which can be considered to be cut-off point between elastic changes and plastic changes. As shown in fig.5. It can be inferred that $(\theta+\mathrm{A}) / \mathrm{A}$, ie GSI, should be not exceed 1.05 .

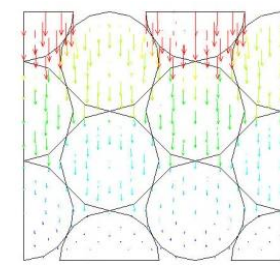

(a) displacement

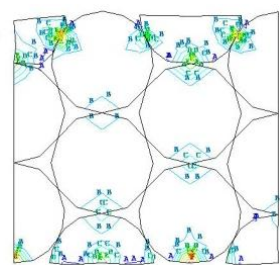

(b) plasticity stress

\section{Results of GSF.}

Fig.5 Partial enlarged vector diagram $(\theta+\mathrm{A}) / \mathrm{A}=1.06$

The parameters are the same with GSI in calculating GSF. Numerical simulation model and boundary conditions are shown in fig.6(a).

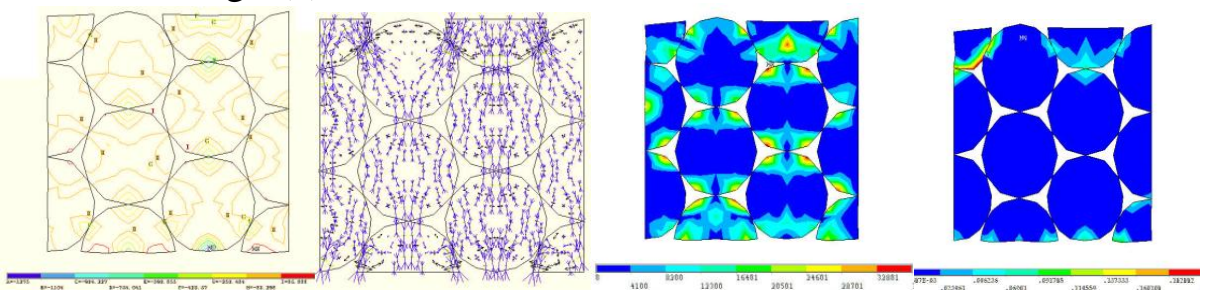

(a)Model (b)principal stress (1.0) (c)principal strain (1.0) (d)principal stress(1.3) (e) principal strain(1.3)

Fig.6 Model and Partial enlarged vector diagram (0.7MPa)

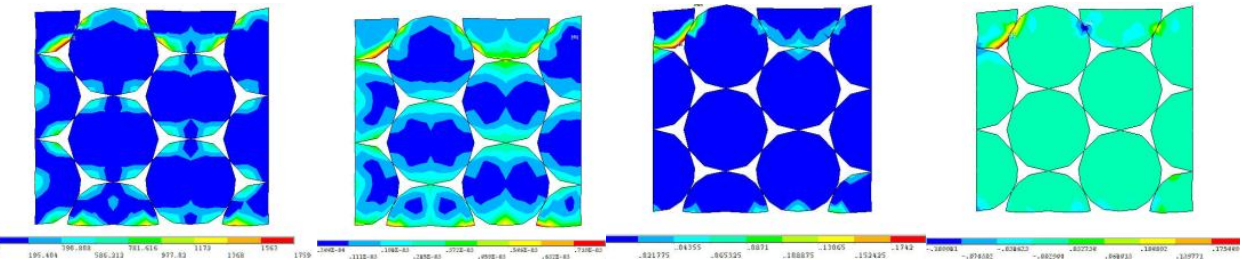

(a) principal stress (1.5) (b) principal strain (1.5) (c) principal strain (1.8) (d) principal strain inXY (1.8)

Fig.7 Partial enlarged vector diagram (0.9Mpa、1.1Mpa)

The vertical pressure equals $0.7 \mathrm{Mpa}$ in fig.7, the GSF value equals 1.0 in (b)(c), the GSF value equals 1.3 in (d)(e). The vertical pressure equals $0.9 \mathrm{Mpa}$ and the GSF value equals 1.5in fig.8(b)(c). The vertical pressure equals $1.1 \mathrm{Mpa}$ and the GSF value equals 1.8 in fig.8(d)(e).

As shown in fig.6 and fig.7, changing the parameters (pressure stress, GSF) inluenced the value of stress, strain ,displacement and deformation.It is possible to simulate the physical properties of particles by changing the parameters. Increasing the GSF assited in developing dynamic pressure, shearing strength and compaction. SGC increases to 1.8, physical properties of asphalt mixture shifted from the linear elastic range to elastic-plastic deformation, asphalt mixture particles began to appear broken, and compaction began to appear not obvious .

The relationship between $S_{\mathrm{G}}$ and $\mathrm{W}$ can be inferred by Cramer method. As shown in Eq. 2 .

$$
\mathrm{S}_{\mathrm{G}}=(1.85 \times \mathrm{W} \times \mathrm{L}) /(\mathrm{A} \times \mathrm{h}) \quad \text { Eq. } 2
$$

$\mathrm{GSF} \geqslant(1.85 \times 1.3) / 2=1.2$. To avoid the plastic deformation, in order to guarantee the stability of materials, GSF should be greater than 1.3.

\section{Entity engineering}

The results of experiment with field cores of rut section in GZ expressway are shown in table 4. The results indicated that the different field core in location and severity in GZ expressway produces similar numerical range of GSI and GSF, which is GSI should be not exceed 1.05 and GSF should be exceed 1.3. 
Table 4 The results of rotary shear test in GZ expressway

\begin{tabular}{|c|c|c|c|}
\hline Structural layer & The compaction times (lap) & GSI & GSF \\
\hline \multirow{4}{*}{ The top layer } & 284 & 1.07 & 1.54 \\
\cline { 2 - 4 } & 202 & 1.05 & 0.97 \\
\cline { 2 - 4 } & 300 & 1.03 & 2.04 \\
\cline { 2 - 4 } & 262 & 1.05 & 1.52 \\
\cline { 2 - 4 } $\begin{array}{c}\text { The following } \\
\text { layer }\end{array}$ & 156 & 1.12 & 1.04 \\
\cline { 2 - 4 } & 244 & 1.08 & 1.27 \\
\cline { 2 - 4 } & 320 & 1.05 & 2.21 \\
\hline
\end{tabular}

\section{Conclusions}

This study simulated the compacting process of asphalt mixes based on GTM, and analyzed the displacement, stress and strain to changes in mold in order to reveal the physical properties during compacting by using discrete element theory.

The results indicated that the design method based on GTM is reasonable and adaptability, and the basic requirements that GSI must be not exceed 1.0,and GSF must exceed 1.0 is scientific. What is more, the study presents the reasonable value range of design parameters to GSI and GSF for engineering application, that is GSI should not exceed 1.05, and GSF should exceed 1.3.

\section{Acknowledgements}

This work was financially supported by science and technology projects of Guangdong province transportation hall (2011-02-001)

\section{References}

[1] J. B. Sousa, J. Harvey, L. Painter, J. A. Deacon, and C. L.Monismith, "Evaluation of Laboratory Procedures for Compacting Asphalt -Aggregate Mixtures", Report No. SHRP-A-UWP=91-523,Strategic Highway Research Program, National Research Council,Washington D. C, (1991).

[2] A. Kumar and W. H. Goetz, "The Gyratory Testing Machine as a Design Tool and as an Instrument for Bituminous Mixture Evaluation", Journal of the Association of Asphalt Paving Technologists, Vol. 43, pp. 351-371 (1974).

[3] L. Tashman (2000), "Internal Structure Analysis of Asphalt Mixes to Improve the Simulation of Superpave Gyratory Compaction to Field Conditions", Ms. Thesis, Washington State University, Pullman.

[4] SHRP (1994), "Level One Mix Design: Material Selection, Compaction, and Conditioning" SHRP-A-408, Strategic Highway Research Program, National Research Council, DC.

[5] Standard Test Method for Percent Air Voids in Compacted Dense and Open Bituminous Paving Mixtures, D3203-94, Annual Book ofASTM Standards, Vol. 04.03, American Society for Testing and Materials.

[6] Wu Chuanhai.New indexes for high-temperture performance evalution of asphalt mixture[J].

Science Technology and Engineering,2011,11(4):1264-1268 